\section{Sobre expedicionarios y ranqueles. Aproximación a una serie universitaria argentina}

Alejandra F. Rodríguez ${ }^{(1)}$

Resumen: En este artículo se analizan aspectos contextuales, narrativos, dramáticos y estéticos de la serie Otra excursión a los indios ranqueles (2017), producida por las universidades nacionales de La Plata, La Pampa, Río Cuarto y Córdoba.

Se reflexiona sobre las identidades construidas por el audiovisual, considerando los distintos elementos estructurales que combina: testimonios de especialistas, escenas recreadas de la obra literaria Una excursión a los indios ranqueles de Lucio V. Mansilla (1870) y cuadros musicales. Se sostiene que cada uno de estos elementos aportan estrategias específicas de vinculación con el conocimiento y el afecto. Asimismo, se postula que debido a la función formativa de la serie, los testimonios se construyen desde una puesta en escena que resalta su confiabilidad y experticia y que la dramatización de fragmentos textuales articulados con los interrogantes y las reflexiones de los especialistas oficia de versión de la historia en los términos planteados por Rosenstone (1997).

Por su parte, la serie encuentra una estrategia hacia la afectividad, definiendo un espacio donde se diluyen distinciones rígidas entre emoción/información, a través de la performatividad de la propuesta musical.

Palabras clave: serie universitaria - Lucio V. Mansilla - pueblos originarios - audiovisual - frontera.

[Resúmenes en inglés y portugués en la página 254]

(1) Magíster en Sociología de la Cultura y Análisis Cultural (UNSaM). Profesora en Enseñanza Media y Superior en Historia (UBA). Profesora adjunta regular e investigadora del Centro Historia Cultura y Memoria de la Universidad Nacional de Quilmes (UNQ). Dirige el proyecto I+D "Historia y fuentes audiovisuales: actores sociales, acontecimientos y procesos en las pantallas argentinas (1940-2015)". Es directora del Diploma de Posgrado y de la Maestría en Historia Pública y Divulgación Social de la Historia de la UNQ. 


\section{Breve introducción}

En este artículo se analizará la serie Otra excursión a los indios ranqueles, que se estrenó el 12 de octubre de 2017 en simultáneo en todos los canales universitarios del país ${ }^{1}$ y está basada en la obra literaria Una excursión a los indios ranqueles, del escritor, político y militar argentino Lucio V. Mansilla. Esta última se publicó, a modo de apostillas, por primera vez en 1870 en un diario de la época y se reeditó cientos de veces en forma de libro, bajo distintos sellos editoriales.

Según la sinopsis, la serie "cuenta las aventuras de un hombre de mundo en confrontación amistosa con otra cultura que es tratada como primitiva. Mansilla pone en tela de juicio permanentemente: quiénes son los civilizados y quiénes los bárbaros" (Plataforma Mundo $\mathrm{U}$ [sitio web]).

Se trata de una pieza de la televisión universitaria que se enmarca en las políticas públicas de fomento a la producción audiovisual, impulsadas a partir de la sanción de la Ley 26.522 de Servicios de Comunicación Audiovisual de 2009. Desde entonces, las universidades nacionales obtuvieron un marco legal para constituirse en licenciatarias de televisión.

Según el planteo de Ayala, Nicolosi y Fleman (2019), el desarrollo de las señales universitarias fue posible gracias a dos factores relevantes: por un lado, la aprobación de un marco legal que permitió la implementación de la Televisión Digital Abierta (TDA), lo que posibilitó que las ficciones seriadas televisivas llegaran a nuevos públicos y hogares; y, por otro, el acompañamiento continuo de la Red Nacional Audiovisual Universitaria (RENAU).

La producción que aquí se analiza fue realizada por profesionales de las universidades nacionales de Córdoba, La Plata, Río Cuarto y La Pampa. Estas cuentan con canales de televisión propios y decidieron aunar esfuerzos y coordinar sus dinámicas de producción para llevar a cabo la realización de una serie de temática histórica. Dicha apuesta al trabajo conjunto posibilitó que este audiovisual contara con una producción importante para los estándares de los audiovisuales universitarios argentinos, lo que se evidencia en el hecho de que en el rodaje participaron treinta actores, cincuenta extras, ocho bandas de rock, veintiséis técnicos y más de veinte especialistas de todo el país. Sin duda, la serie marca un momento histórico excepcional para la producción de contenidos con fines de divulgación.

La serie articula el relato documental con la recreación ficcional de tema histórico y a nivel de la producción esto se resolvió con la existencia de dos directores: Gustavo Alonso en contenido y dirección documental y Jerónimo Carranza en la dirección, realización y edición de la parte ficcional.

Si bien la serie se publicita como docuficción, es posible pensar esta pieza desde la categoría de "no ficción", puesto que, siguiendo a Carl Plantinga (2014), lo que diferencia la ficción de la no ficción es la postura asertiva que implica afirmar que el estado de cosas presentado ocurre en el mundo real. La pieza que analizamos aborda la obra y vida de Lucio V. Mansilla ${ }^{2}$, un personaje histórico, a través de la combinación de los testimonios de diversos especialistas con la recreación audiovisual de fragmentos de su obra: Una excursión a los indios ranqueles. En este sentido, sostenemos que el enunciado se presenta como forma de interpretación de la obra de Mansilla, así como de los sucesos históricos que en el libro se 
despliegan. Seguimos a Plantinga (2014) cuando postula que: "En general, los documentales dramatizados implican una postura global de analogía afirmativa, en las que hacen afirmaciones por analogía (escenificar, dramatizar) en lugar de directamente" (p. 48).

De este modo, es posible sostener que la postura asertiva se mantiene y que la dramatización de fragmentos textuales articulados con los interrogantes y las reflexiones de los especialistas oficia de versión de la historia en los términos planteados por Rosenstone (1997). Asimismo, en el presente trabajo se reflexiona sobre las identidades construidas por el audiovisual, considerando que este está constituido por distintos elementos estructurales como son las entrevistas, la recreación de fragmentos del texto fuente y los cuadros musicales. Cada uno de estos elementos aporta estrategias específicas de vinculación con el conocimiento y el afecto.

\section{La estructura}

La serie aborda la obra Una excursión a los indios ranqueles a partir de un recorte temático mediante el que se desglosa el escrito del siglo xix en capítulos centrados en diferentes temáticas, que proporcionan un eje específico a la narración: capítulo 1. "Quién es Lucio Mansilla", capítulo 2. "El idioma y el lenguaraz", capítulo 3. "La mujer y el amor", capítulo 4. "Civilización o Barbarie", capítulo 5. "Mariano Rosas Paine: el elegido", capítulo 6. "Parte de la religión", capítulo 7. "La frontera y el desierto" y capítulo 8. "La gran junta: el final”. Como se señaló, en esta propuesta se alternan especialistas en la obra de Mansilla con aquellos que lo son en el contexto histórico, entre los que se cuentan académicos del campo de las letras, de la historia, de la antropología, de la sociología, de la comunicación, así como archivistas y directores de museos: Cristian Alarcón (periodista-UNLP), Federico Albornoz (Letras-UNC), Silvia Ametrano (Museo de Ciencias Naturales de La Plata), Andrea Bocco (Letras-UNC), Daniel Cabral (hablante ranquel, desarrollador de la lengua), Julieta Canedo (Historia-UNC), Carlos Ciappina (Historia-UNLP), José Depetris (especialista en la obra de Mansilla), Mariano Dubín (Letras-UNLP), Claudia Farías (Cultura de Santa Isabel, La Pampa), Inés Farías (directora del Archivo Histórico Fray José Luis Padros, Río Cuarto), Omar Isaguirre (director del Archivo Histórico Municipal de Río Cuarto), Alejandra Laera (Letras-UBA), Juan Laxagueborde (sociólogo y editor de la revista Mancilla), María Rosa Lojo (Letras-UBA), María Pía López (Letras-UBA), Esteban López Brusa (Letras-UNLP), Cecilia Corona Martínez (Letras-UNC), Florencia Minici (UBA, directora de la revista Mancilla), Graciana Pérez Zavala (Historia-UNRC), Fermín Rodríguez (Letras-UBA), Claudia Salomón Tarquini (Historia-UNLPam), Ramón Tarruela (Editorial Mil Botellas) y Mirta Zink (Historia-UNLPam).

La serie explora al personaje, su época y su obra a partir de preguntas globales y particulares que solo se explicitan a través del diálogo entre las respuestas de los especialistas y la acción dramática.

Tal como se señaló anteriormente, la dirección de las entrevistas estuvo a cargo de Gustavo Alonso. Al respecto, Jerónimo Carranza (25 de marzo de 2021) señaló que 
[...] se desdobló el equipo, Gustavo Alonso que tiene mucha experiencia en el documental, se encargó de las entrevistas, todo el aspecto estético lo coordinaba yo (Carranza), diseñamos una forma de encarar las entrevistas, un cierto criterio de puestas de cámara y él fue el encargado de realizar las entrevistas. Pero, a la vez, también había entrevistas que se hacían a cargo de la Universidad de Córdoba o de La Pampa, con distintos docentes o investigadores de esas universidades y en ocasiones él (Alonso) iba sin el equipo de La Plata, y el equipo lo ponía la Universidad de Córdoba o la Universidad de La Pampa. Alonso articulaba un poco la idea estética que llevábamos desde acá con lo que se podía hacer desde ahí y trataba de darle el aspecto, la onda, a esas entrevistas. Lo interesante es que la mayoría de las entrevistas se hicieron posteriormente a tener la ficción rodada.

Es decir que el trabajo de análisis del texto fuente y su posterior selección y guionado con vistas a la producción de la recreación audiovisual de la obra funcionó como insumo para organizar muchas de las entrevistas. Al respecto, el director señaló que la idea original era que la recreación ficcional fuera un veinte por ciento de la serie, pero esta idea fue cambiando y ganando más espacio en la pantalla. De este modo, las entrevistas fueron fragmentadas y montadas ocupando un tiempo similar al de la recreación en la pantalla, lo que permitió lograr un equilibrio dialógico entre ambas narrativas ${ }^{3}$.

En términos estructurales es posible sostener que en la construcción de la serie predomina la voz formal, es decir, se construye una autoridad epistémica que descansa en las respuestas de los expertos a preguntas no explicitadas en cuadro, pero que están vinculadas a los temas planteados en la recreación de la obra. Con esta estrategia se pone en juego el conocimiento especializado que se comparte con el espectador en un montaje que le otorga dinamismo. La serie "afirma que ciertos estados de cosas son verdaderos, y los explica. Envuelve dichas aseveraciones en una estructura de información que implica que el conocimiento del tema no es únicamente posible, sino que es comunicado en la película" (Plantinga, 2014, p. 153).

Debido a la función formativa de esta serie, los testimonios se construyen desde una puesta en escena que resalta su confiabilidad y experticia. Los planos que presentan a los profesionales son abiertos y los exhiben en su contexto; a modo de ejemplo, una de las primeras entrevistadas, la historiadora Mirta Zink es seguida por la cámara desde la calle, se la ve franquear la puerta de la UNLPam y adentrarse en la biblioteca. La mayoría de los expertos son entrevistados en sus instituciones de pertenencia (universidades, archivos y museos) y se los muestra rodeados de libros. Aquellos que aparecen en espacios más informales como casas o confiterías aparecen acompañados de algún atributo que da cuenta de su saber: la cámara enfoca un primer plano del libro abierto o del documento de la computadora. En la mayoría de los casos se exhibe el libro en cuestión y la puesta y manipulación en pantalla lo convierte casi en un objeto dramático hacia el interior de las entrevistas.

En el caso de los directores de Archivos interesa mostrar la fuente primaria, las fotografías de Masilla y de los miembros de la excursión, patrimonio del Museo de Río Cuarto. En el caso de Inés Farias, directora del Archivo Fray José Luis Padros, la locación elegida es 
doblemente significativa, ya que no solo la entrevistada da testimonio desde los bancos de la iglesia, lo que refuerza la temática abordada en su exposición sobre la religiosidad y el rol de los clérigos en la expedición, sino que además la cámara la sigue hacia el interior del templo hasta dar con una sección del archivo, donde se muestra en el cuadro la carpeta con los manuscritos con los planes de Donatti y Mansilla.

De esta manera, las locaciones elegidas colaboran en la definición de estas identidades, se trata de intelectuales universitarios intra o extra muros. Al respecto, Carl Plantinga (2017) sostiene que:

[...] por lo que concierne al retrato de personas, no podemos negar que el documental, aun focalizando la atención sobre individuos reales, los "caracteriza" ya que les construye una imagen y les proporciona una identidad más que simplemente imitar $\mathrm{u}$ ofrecer un testimonio transparente de "quiénes son dichos protagonistas" (p. 48).

Cabe señalar que solo hay dos testimonios que no pertenecen a este grupo de especialistas: el de Claudia Farías, presentada como descendiente ranquel y funcionaria del área de Cultura de La Pampa, y Daniel Cabral. La primera aporta una voz que une ese pasado con el presente mediante un viaje que la lleva a las tierras ranquelinas; allí su figura vestida de negro se recorta en dos planos sobre el amarillo pastizal pampeano que la enmarca. Allí sostiene ideas acerca de la función de espionaje de la excursión, postura que luego es relativizada por la especialista que la sucede en el montaje. El audiovisual incluye la entrevista a Daniel Cabral, facilitador de la lengua ranquel, quien dio testimonio de sus conocimientos e historia en numerosos documentales recientes. En este único caso la cámara lo acompaña y observa las condiciones de precariedad en las que habita; de esta manera, el espectador puede establecer un vínculo entre esa historia y el presente.

Por último, la serie cuenta con un tercer elemento estructural que es la inclusión de cuadros musicales, tema que desarrollaremos más adelante.

\section{Sobre la recreación histórica}

Sostenemos que la definición de las formas invita a la reflexión sobre el poder del audiovisual que, aun cuando adapta una obra literaria, que podríamos pensar como obra de ficción, logra situar la anécdota en un determinado contexto histórico -con la elección de un paraje particular, de un uniforme de época y de determinados utensilios- $y$, por ende, en determinado verosímil ${ }^{4}$, poniendo así a consideración la representación como versión sobre la historia.

En este sentido, podría pensarse que el cartel cepiado que abre y cierra los capítulos, a la vez que da cuenta de las universidades e instituciones que participaron en la realización, anuncia la tensión entre verdad y verosímil, entendida como la tensión entre el documento y la recreación. Las letras iniciales rezan que la voz en off reproduce con fidelidad el 
texto de Mansilla; a continuación, se sucede una animación de imágenes que ponen en primer plano a los actores que interpretan los personajes históricos... Sin embargo, algo de lo documental se hace presente a través de las fotografías de archivo, donde se dejan ver rostros -entre ellos el de Mariano Rosas- y cuerpos de indios vencidos que insisten desde el fondo como sedimento.

Respecto a la dramaturgia, cabe señalar que Mansilla, interpretado por Facundo Ábalo, es quien lleva adelante la acción y su voz en off presenta los personajes con los que interactúa en ese viaje que modificará su perspectiva sobre el "desierto y sus habitantes". El personaje está presente en la totalidad de las escenas. El primer capítulo abre con el escritor en su despacho, iniciando la comunicación epistolar con su amigo Santiago Arcos, en la que da cuenta de la excursión a tierra ranquel. El contrapunto imagen-palabra se establece en el primer segundo: su voz en off relata la vida hedonista y cosmopolita llevada en las capitales del mundo, a la vez que las imágenes de la travesía en una tierra enlodada generan el contrapunto visual. Así comienza este capítulo que oficia como resumen y presentación de los siguientes.

Mansilla galopa, Mansilla escribe, Mansilla piensa, Mansilla habla, pero sin diálogos. ¿Cómo se relaciona la imagen con el discurso verbal? Conocemos su pensar y sentir a través de una voz en off que recrea sus escritos; solo en un par de capítulos realiza algún breve intercambio dialógico o enuncia alguna expresión en directo.

El realizador (Carranza, 25 de marzo de 2021) sostiene que con esta estrategia buscó sortear la incomodidad de resolver el modo de hablar de esos grandes hombres en el siglo xix y refiere al rechazo que le producen algunos filmes argentinos de tema histórico cuando presentan modismos actuales, razón por la cual eligió reemplazar la comunicación directa por la reflexión que el militar expresa en sus escritos; de esta forma, además, se apega al texto fuente, tal como fue escrito.

Es posible agregar que esa operación que produce el desdoblamiento de voz y acción refuerza la idea de que se está participando de la mirada que el escritor tiene sobre el mun$\mathrm{do}^{5}$. Esta perspectiva adquiere un nuevo espesor cuando el protagonista aparece al borde del cuadro, como observador. A modo de ejemplo, en el capítulo 5, minuto 9, su figura casi a escondidas y desenfocada es la que invita a observar el rodeo del cual participa el jefe ranquel. En otra ocasión, en el capítulo 2 se reitera esa mirada analítica, pues, desde esa posición distante y observadora, describe a su guía Mora como si fuera un objeto de estudio, con una ajenidad que luego se rompe cuando el personaje se mueve, cambia de lugar y se acerca al agua donde están refrescándose sus hombres.

La estrategia se reitera en otra secuencia: Mansilla, desde un lugar semioculto, mira a Carmen la lenguaraz enviada por Mariano Rosas; así, la mujer observada se convierte en extensión o metáfora de la tierra que se codicia y desea conquistar. A su vez, en el capítulo 3 su mirada enfocada en el anillo de bodas es la que permite proyectar y enfocar su vista en esas mujeres nativas, dando lugar a la reflexión sobre lo equiparable de la belleza de las mujeres de ambos mundos.

Por su parte, y como se señaló con anterioridad, la dificultad de resolver de un modo apropiado el habla del personaje de Mansilla indujo al realizador a reforzar el tono introspectivo y reflexivo mediante el uso de la voz en off. Esta estrategia no se replicó a la hora 
de representar a los grupos indígenas. En este caso, la representación se inclina por la voz directa, que en algunas ocasiones es reemplazada o acompañada por gritos y sonidos que no conforman una lengua. No obstante ello, el tema del lenguaje es problematizado tanto en los testimonios de especialistas como en la recreación y constituye el eje del capítulo 2 que se titula "El idioma y el lenguaraz".

A los 16 min de este capítulo, en un contexto de cierta tensión dramática, en el que una comitiva de nativos rodea al grupo de Mansilla y "atropella" a uno de los religiosos, el ranquel que encabezaba la partida dice: - Esto soy, Cañupay, indio guapo, capitanejo de Rosas, mientras gritos hostiles ganan el primer plano sonoro. Luego, la voz en off de Masilla apunta - Junto a la palabra huinca se oyeron otras groseras. A continuación, el capitanejo desafía a Mansilla y dice - dando caballo huinca - huinca pagar por pasar por mi tierra. A lo que el coronel responde -ándate al diablo. Acto seguido, el montaje presenta a la yegua despanzurrada y los indios sacando de sus vientre los órganos y comiéndoselos crudos. Mientras la reflexión de Mansilla remite a la sangre todavía caliente del animal, los rostros ensangrentados por la ingesta son puestos en primer plano.

De esta manera, la puesta en escena que estaba al servicio de la diferencia se desliza hacia la construcción de la otredad y se hace eco de una visualidad hegemónica, que acompañó a los procesos de expansión territorial y colonial durante gran parte de los siglos XIX y XX, que animaliza a los pueblos originarios ${ }^{6}$.

Es posible pensar esa escena desde el planteo de Raymond Williams acerca de lo "residual", que hace referencia a aquello que "ha sido formado efectivamente en el pasado, pero todavía se halla en actividad dentro del proceso cultural; no sólo -y a menudo ni eso- como un elemento del pasado, sino como un efectivo elemento del presente" (Williams, 1980, p. 144). En el mismo sentido, es posible establecer un vínculo con aquella forma de expresión que planteaba el filme pionero El último malón (Greca, 1917) y algunas secuencias donde la recreación se hace eco del habla elemental y mal conjugada. Al respecto, sostiene Daniela Greca (2014):

Así, es el propio Greca quien lleva el lenguaje oral de los indígenas al texto escrito que aparece en los intertítulos de la película, en los cuales, a pesar de la pretensión de "transcribir" aquellas voces con cierta "textualidad", resulta inocultablelaincidenciadevisioneshegemónicasquelessonajenas. Deestemodo, se registra una tensión entre, por una parte, la intención de criticar y denunciar la situación en que viven los indígenas y, por otra, la influencia de una ideología etnocentrista ampliamente extendida en el período y en la que Greca se encuentra inevitablemente inmerso (p. 46).

Aunque también es necesario destacar que el chegundum, o idioma ranquel, se visibiliza tanto en la voz de Mansilla -quien al inicio del capítulo intenta pronunciar palabras en ese idioma y da cuenta de la dificultad de la tarea- como en la voz de Carmen, la lenguaraz. Por fuera de la recreación, el idioma cobra vida a través del testimonio de Daniel Cabral. Es así que, a pesar de la complejidad, la lengua de los ranqueles logra inscribirse en esta narración. 


\section{De identidades, fronteras y mestizajes}

Respecto a las locaciones que permitieron la puesta en escena de la serie cabe señalar que, en la primera etapa, la filmación se concentró en la Comunidad Ranquel Canoe, ubicada a pocos kilómetros de Santa Rosa, La Pampa. En las escenas rodadas allí participaron varios miembros de la comunidad. Posteriormente, el equipo de trabajo se trasladó a La Plata, al Batallón 601 de City Bell. En este predio, se desarrollaron gran parte de las jornadas de rodaje (Contexto, 2018).

Es desde estas locaciones que la serie propone gran parte de la inmersión auditiva en la frontera. Se otorga un primer plano sonoro a aquellos efectos que dan cuenta de lo campestre, pájaros, viento, trote y relinchos de caballos. La música incidental que acompaña los ocho capítulos fue realizada por el director Jerónimo Carranza junto a Aníbal Iguarán, con bombo legüero y guitarra electroacústica; esta contribuye a dotar de extrañeza a ese paisaje de frontera.

A nivel dramático, una marca de la inmersión en la frontera la constituye la aparición de los sonidos de instrumentos indígenas (vientos) que asoman siempre como disonantes. En algunas secuencias, cuando el protagonista se adentra en esa tierra indígena, los sonidos se transforman en diegéticos, y el espectador puede ver y en otras, intuir los instrumentos y quiénes los ejecutan.

El espacio en el que transcurre "la excursión" se construye, tanto a nivel de la trama como a nivel estético, como zona porosa, conflictiva, de negociación y de intercambio. El uso de filtros que logran agrietar y curtir los rostros de los actores, así como las decisiones sobre su vestuario, contribuyen a la idea de mestizaje. Los personajes visten prendas que dificultan la identificación clara de los bandos: ponchos y bombachas son frecuentes en la tropa, así como casacas y otros elementos militares en la indiada. En ese sentido, a un notable trabajo de reconstrucción artística e histórica se suma otra capa de sentido que vincula esta serie universitaria con el cine clásico y es el hecho de que los uniformes que se usaron para el rodaje son los mismos que se confeccionaron y vistieron para la filmación de La guerra gaucha (Lucas Demare, 1942). Es decir, representación sobre representación, pliegue sobre pliegue de la historia.

Continuando con el análisis de los elementos estéticos, se puede destacar la luminosidad naturalista de las puestas a cielo abierto; el horizonte ocupa gran parte del cuadro y en dicho horizonte la tierra es el objeto preponderante de la cámara. A modo de ejemplo, es posible señalar que en momentos que se recrea la reunión con los caciques ranqueles más importantes, se alternan las tomas a ras de la tierra; así, el movimiento del pasto cede el lugar al movimiento de la pequeña tropa, tomada cenitalmente. Esto dimensiona la pequeñez humana en el gran paisaje de la pampa. Cortando esa inmensidad, Mariano Rosas y Mansilla galopan al encuentro mutuo.

La idea del paisaje como desierto, tan evocado en los filmes tradicionales de frontera, es casi inexistente en esta producción, que privilegia una fotografía donde el verde domina el cuadro y los planos que dan cuenta de la aridez o de un entorno desértico se dosifican y utilizan en algunas pocas secuencias y con sentidos muy precisos. 
En una de esas pocas ocasiones "el desierto" se actualiza en imagen de una tierra yerma y agrietada. Esto ocurre cuando Mansilla dice:

-Aquellos campos desiertos e inhabitados tienen un porvenir grandioso, y con la solemne majestad de su silencio piden brazos y trabajo. ¿Cuándo brillará esa aurora color de rosa? ¡Cuándo! cuando los ranqueles hayan sido exterminados o reducidos, cristianizados y civilizados.

Minutos después y luego de dar cuenta de la necesidad y la inminencia de la llegada del ferrocarril, la voz del protagonista enuncia: - Cuando estas tierras estén civilizadas solo va a quedar eso, mientras el plano actualiza el árido territorio.

Otra de las apariciones del "desierto" en el cuadro ocurre en el capítulo 7, 5 min $36 \mathrm{~s}$. Al tiempo que uno de los especialistas entrevistados, Carlos Ciappina, sostiene que "desde la perspectiva de la elite, ese territorio está vacío, desperdiciado...", la cámara se hace eco de sus palabras, exhibiendo el pastizal pampeano amplio y amarillento. Mientras la banda sonora anticipa un clima de tensión, los acordes van aumentando su vibración hasta que en ese horizonte se recorta un indio montado en su caballo banco; según la voz en off, es quien imparte el miedo en la región. La idea se completa por metonimia visual: el indio queda resumido en el primer plano de su puño y su lanza.

Al decir de la voz de Mansilla, se trata de un indio gaucho, es decir un indio sin ley ni sujeción a nadie... y ante esta descripción la música se convierte en malambo, que sirve para caracterizar y reforzar la presencia del temido personaje.

Cuando en el plano aparece Mansilla, se diluyen los bombos, para luego reaparecer junto al sonido de los cascos de caballos que galopan furiosos cuando se adentra en tierra indígena. A ese paisaje sonoro se le suman los instrumentos de viento, relinchos, gritos y disparos.

La voz de Mansilla dice, refiriéndose a los hombres que contrató para la misión de expulsar al indio Blanco:

- [...] los fariseos que crucificaron a Cristo no podían tener una facha de forajidos más completa, estaban dispuestos a derramar sangre o a jugarse la vida; es triste decirlo, pero kilómetros y kilómetros de frontera se ha ganado para la civilización por la acción de verdaderos bárbaros... llegaron a robarme a mí y no debí sorprenderme... ¿Qué motivaba a estos animales? Su trabajo fue tan sucio y tan salvaje que el indio Blanco huyó y nunca más se supo de él. A esas cosas debí rebajarme para defender la frontera.... Al final entre el indio Blanco y yo no debía haber mucha diferencia.

Por primera vez, el malambo acompaña también la reflexión del hombre blanco, en el momento que la dramaturgia lo ubica del lado de la barbarie.

Cabe señalar que la representación de los pueblos originarios que propone la serie no es monolítica; en ocasiones, el guion habilita las líneas en las que el texto fuente destaca 
la especificidad e importancia de la cultura ranquel y esto se acompaña de la puesta en cuadro del trabajo en adobe, de la exhibición de la belleza de la orfebrería desplegada por el cacique Ramón Cabrera o de la exquisitez del agasajo que le brinda el cacique Epumer a Mansilla. Una construcción que está tensionada desde el propio texto fuente, que en ocasiones los presenta asociados a lo crudo, al salvajismo, como puede observarse en la escena descripta anteriormente.

Capítulo tras capítulo, la serie va presentando a los caciques y capitanejos hasta llegar al capítulo 4 donde se da el esperado encuentro con Mariano Rosas (Panguitruz), el más influyente de los ranqueles. La tropa de Mansilla es rodeada por los hombres Rosas y el travelling circular ralentiza las imágenes, metaforizando esos instantes interminables para los soldados, que desconocían lo que el futuro les depararía. Finalmente, la escena cobra ritmo, acompañada de los gritos de la indiada que rompe fila para dar paso al cacique. Un contrapicado da cuenta de Mariano Rosas montado en su caballo. Luego, en los saludos, la cámara devuelve la simetría con Mansilla y la puesta construye una suerte de camaradería entre ambos, que se reitera en las escenas de rodeo y las del interior de la tienda del cacique.

Mientras estas imágenes trascurren la voz en off relata la genealogía mestiza del cacique y su historia en ambos mundos, el hispano criollo y el indígena. A nivel dramático Panquitruz funciona como coprotagonista, como contrafigura, que no alcanza a constituirse en antagonista, pues la historia con mayúsculas debilita esta función dramática. No está en el "desierto" ni tampoco en la voluntad de Mariano Rosas ser la fuerza que impide a Mansilla concretar su cometido de paz.

Si bien toda la representación esta mediada por la mirada que propone el texto fuente, la cámara en determinados momentos los construye de similar estatura, como iguales; $\mathrm{y}$, tanto desde la reconstrucción audiovisual como desde el discurso académico, se sostiene la idea de la gran politicidad de los ranqueles y de las habilidades de sus líderes para la negociación.

La caracterización del cacique se profundiza en el capítulo 5, que abre con el militar buscando algo entre sus libros hasta dar con una foto y, de esta manera, el retrato del verdadero Mariano Rosas se actualiza en la recreación histórica. Mientras su voz en off lo describe, un primer plano da cuenta del actor que lo interpreta. Al ampliarse el cuadro se observa a Paquitruz con una machi, quien le indica no asistir a la reunión con el coronel. La entrevista de Mirta Zink que se monta a continuación refuerza la idea y, además, otorga relevancia al rol de las machis, una de las figuras femeninas que tiene lugar en una trama donde la acción se encarna en hombres. Sin embargo, el encuentro se produce y el enunciado sostiene la idea de lo particular de ese momento histórico en que todavía era posible el diálogo, la convivencia, aun en tensión, aún en conflicto. Esta idea cierra en el capítulo 8 con la gran junta: el final.

El capítulo inicia con un sueño y cierra con la celebración del acuerdo. El primero remite a Mansilla en la previa a la gran junta con los líderes ranqueles: cuando apoya la cabeza en la tierra, cambia el clima sonoro. En los sueños, que se vuelven pesadillas, el contorno natural se desvanece para dar lugar a una ceremonia. En ella el fuego ilumina las ramas de los árboles, enrareciéndolos y asemejándolos a terminales nerviosas. El bombo se convierte en latido y ese latido, en galope del cacique Mariano Rosa que atraviesa la pampa. 
Por unos breves segundos, hacia el interior de su pesadilla podemos advertir un ritual, la música ranquel/mapuche se actualiza, con los efectos de vientos, percusión y canto de la machi o chamán. Al igual que varios de los documentales contemporáneos -como, por ejemplo, El país del diablo (2008) y Tierra adentro (2011)-, este audiovisual también da cuenta de la celebración de un ritual, no obstante, a diferencia de los filmes señalados, el rito no funciona como nuevo amanecer nguillatún o alegoría del porvenir, sino que anuncia el atardecer, el clímax de la serie: la gran junta del coronel con los líderes de los diferentes grupos ranqueles. La puesta en escena de la celebración nocturna, luego de largas horas de debate y después de haber escuchado todas las voces, propone un final que no logra constituirse en feliz, pues el espectador sabe, por las voces de los especialistas, que el tratado no logrará torcer el destino de exterminio que les depara el futuro.

La voz de Mansilla concluye: "[...] solo habrá justicia cuando todos seamos iguales ante la ley porque a fin de cuentas ni Ramon, ni Epumer, ni Baigorrita, ni Coñuepán, lo supieron en su momento, pero con ese apretón de manos de Mariano Rosas, nosotros, todos nosotros, nos hicimos de la tierra". Mientras un paneo vertical se despega hacia las estrellas.

\section{Música, identidades y afectos}

La elección política y poética de las canciones que acompañan cada capítulo merecen la reflexión sobre el lugar de la canción popular y los afectos en este audiovisual.

Fragmentos de las canciones afloran promediando el capítulo y se presentan completas al cierre de este. Se trata de canciones compuestas e interpretadas por los siguientes músicos: Santiago Motorizado de Él Mató a un Policía Motorizado, Sergio Pángaro, Sara Hebe, Shaman Herrera, Gustavo Astarita, Corazones, Teodoro Caminos y Poli, líder de Señor Tomate. Artistas populares y referentes de la escena platense, quienes actúan y participan de la trama caracterizados como indígenas o soldados y ejecutan canciones en vivo, desviándose de su origen y de sus escenarios habituales para asumir nuevas funciones.

El primer capítulo se ve "invadido" por el rasgueado de guitarra que hace de transición hacia la recreación, mientras el entrevistado da cuenta de que el ejército que emprendió la excursión era muy pobre. Se observa llegar a los soldados, quienes se van reuniendo en torno a un fogón, acompañados de guitarras y bombos, recurriendo a una tradición del cine clásico de mediados del siglo xx. Nos referimos a aquellos filmes de frontera que incluían escenas con músicos. Estos cuadros - que en ocasiones no estaban muy bien articulados con la tramaservían a nivel dramático para posibilitar la expresión de los sentimientos de los personajes en la dureza del medio hostil, de la posta, del fortín o de la caravana; y a nivel industrial, para ofrecer a los espectadores el atractivo de contar con los ídolos populares de la radio. Bagualas y zambas se dejaban escuchar, por ejemplo, en Pampa bárbara o El último perro (de Lucas Demare con música de su hermano Lucio, 1945 y 1954)

En este capítulo aflora la canción Semilla de la banda Corazones. Un tema de rock-folk con un ritmo propio del folclore, cuya letra trae la metáfora: una semilla que no prosperó, en el medio de un capítulo que anticipa una excursión destinada a lograr un tratado de 
paz que no la aseguró. En este sentido, la estrategia de inclusión de los cuadros musicales propone mecanismos específicos de la identificación y el reconocimiento generados en la interacción íntima del intérprete y la multitud (Gilroy, 1990). Así, esta serie encuentra una estrategia hacia la afectividad, definiendo un espacio donde se diluyen distinciones rígidas entre emoción/información, a través de la performatividad de la propuesta musical.

En esta búsqueda, quizás la propuesta más rupturista (por el género que presenta) en un audiovisual de temática histórica se encuentre en el capítulo 7 cuando los instrumentos de viento tradicionales dan entrada a la cantante y compositora Sara Hebe, caracterizada como una machi nativa que se impone en el fogón de la tropa de Mansilla.

El fuego ilumina la escena y la enrarece ${ }^{7}$. Sara Hebe rapea con una estructura que podría pensarse como producto de una improvisación (free style), siguiendo un ritmo de $4 \mathrm{x} 4$. Su voz, al comienzo a capela, es acompañada, luego, de una pista instrumental. Así, el rap y el hip hop, asociados a la negritud (por su origen en las comunidades afroamericanas de Estados Unidos), se hacen presentes en ese espacio ranquel de la mano de una rapera nacida en la Patagonia, que fue una de las primeras mujeres del rap en tocar en escenarios particularmente masculinos.

Como señala Simon Frith (1996), en el rap, "la autoridad musical, lejos de disiparse en los fragmentos y sonidos de segunda mano, se fortalece por la atención prestada al acto mismo de citar" (p. 194). Los distintos elementos dislocados se yuxtaponen auditivamente y se destacan en la interpretación, lo que da lugar a la construcción de nuevos significados.

Un cambio ${ }^{8}$

[...]

Yo fui la reina del reviente pero ya somos grandes y pasamos simplemente

Simple de repente, hicieron la campaña en el desierto

Mapuches, Ranqueles, Tehuelches; hay 14 mil muertos

Ancestral es el acierto las almas y el espíritu en el aire no se ven pero son ciertos

No era así lo que tenía que venir, no era así lo que tenía que venir

Sangre de colonia, pampa cuyo Patagonia se habla de raza, ¿Qué raza?

¿La raza que quedó? ¿La raza a la que se le metieron por la sangre?

¿La raza que mataron? a algunos los trajeron, a otros los llevaron

La historia del colono es la verdad que se inventaron

¿Qué pueblos resistieron? ¿Qué suelos invadieron?

Cambiaron el destino el año en que desembarcaron

Ooh, oh, oh-oh-oh, limpiaron el terreno y alguien repobló

¿Quién es el pueblo?

¿Y dónde están mis rasgos que no los veo?

Ooh, oh, oh-oh-oh, limpiaron el terreno y alguien repobló

¿Quién es el pueblo?

¿Y dónde están mis rasgos que no los veo?

Y me ceba, me ceba, me ceba, me ceba 
La caracterización como machi y el fraseo de Hebe dan lugar a una experiencia de la identidad $^{9}$, a la vez que convoca una memoria de la Patagonia como espacio ensangrentado, vaciado y blanqueado por la Conquista del Desierto y de lo que persiste e insiste como falta en esa identidad. Por su parte, la letra pone en agenda cuestiones climáticas y ecológicas que se acercan a muchos de los reclamos vigentes hoy en las comunidades originarias, que denuncian la voracidad del sistema productivo occidental ${ }^{10}$.

La canción sirve de paso a los créditos que, como ya se señaló, pueden pensarse como condensación de la apuesta audiovisual, que tensiona entre verdad y verosímil, entre la trasposición literaria y la reconstrucción histórica.

Por su parte, y abordando la serie como enunciado general, es posible sostener que la puesta en escena de bandas de rock y hip hop locales funciona como actualización de una historia a partir de una experiencia estético musical que apela a una identidad local y actual que interpela a las nuevas generaciones. Las emociones circulan a través de estos cuadros musicales que, a la vez, funcionan como catalizador de diversas temporalidades en una apuesta por sacar la historia de la academia y hacerla atractiva para un público amplio. Porque, como sostiene Rosenstone (1997),

El pasado no solo significa, sino que también sonaba, parecía y se movía. Un atardecer puede que no sea parte de la historia, pero los atardeceres tienen un valor para la gente: han dulcificado corazones, generado esperanzas, calmado temores. Esto también es parte de la historia (p. 172).

Sin duda, la inclusión de las canciones otorga al audiovisual un efecto de anacronismo y de emotividad que comunica las temporalidades de los siglos XIX y XxI.

\section{A modo de cierre}

En el artículo se analizaron algunos aspectos contextuales, narrativos, dramáticos y estéticos de Otra excusión a los indios ranqueles y quedan aún muchos por profundizar, en especial queda pendiente un análisis global del enunciado que focalice en las decisiones sobre las características y los sentidos que habilitan el montaje de la recreación y los testimonios. A lo largo de estas páginas, se ha reflexionado en torno a las formas que adquirió la recreación de la obra de Mansilla, la inmersión visual y auditiva en la frontera y la construcción de las identidades de quienes allí habitan. Se sostuvo que el diálogo con los especialistas construye una postura asertiva, que puede abordarse como versión de la historia, ubicándola en la disputa de sentidos sobre ese pasado. El lugar de enunciación, la universidad pública, funciona como espacio legitimador de un acercamiento historiográfico que da cuenta de que los pueblos originarios despliegan capacidad de agencia y negociación; así como de ideas sobre la frontera como zona de conflicto y también de intercambio; en un contexto histórico específico en el cual el Estado, representado en el coronel Mansilla, enuncia la voluntad de negociar. 
La construcción identitaria que se hace de los especialistas de las distintas disciplinas resalta sus atributos de lectores expertos en la obra de Masilla como en el contexto histórico. En el mundo proyectado por la serie, sus aseveraciones tienen un valor de verdad que se complementa y en ocasiones tensiona con la inclusión de los testimonios de descendientes ranqueles que, por herencia o por definición, encarnan una identidad e historia que se representa. De esta forma, Otra excursión... admite ser leída como documento de este presente en el que la universidad pública elabora un producto que, desde una postura asertiva, afirma que el conocimiento es posible y es comunicable, rompiendo con la solemnidad de la historia como documento, articulándolo con el drama como forma de acercamiento al texto fuente, e invitando a difuminar las fronteras entre la alta cultura de la institución universitaria y la cultura popular con la puesta en escena de bandas de rock y hip hop locales. Retomando el planteo de Ayala, Nicolosi y Fleman (2019) acerca de que las ficciones seriadas universitarias mostraron identidades y problemáticas con diversos arraigos territoriales y locales, que se diferenciaron de las propuestas hegemónicas centradas solo en Buenos Aires, es posible sostener que la serie aporta a la descentralización geográfica tanto desde la puesta en escena como desde las miradas que se ofrecen sobre la historia y la obra de Mansilla. Por su parte, las locaciones pampeanas y platenses están al servicio de una puesta en escena que rompe con cierta iconografía de las tierras ranquelinas, representadas como desierto. $\mathrm{Al}$ respecto, se sostiene que esa perspectiva, acuñada en la literatura e iconografía del siglo xix, se dosifica en el cuadro y hace su aparición cuando la diégesis de la recreación o de las entrevistas problematizan ese espacio.

En esta recreación del texto de Mansilla, se utilizan variados recursos estéticos que refuerzan la idea de que es el punto de vista del protagonista el que da cuenta de ese mundo proyectado. El desdoblamiento de la voz del protagonista contribuye, por un lado, a presentar esa obra como el producto de su reflexión y, por otro, a dotar al relato de un valor de verdad que se ancla en la reproducción textual de fragmentos del texto fuente.

En este sentido, se identificaron diversas estrategias desarrolladas por el audiovisual para hacer verosímil el habla de los personajes y se advirtieron diferencias en la representación de unos y otros. La presentación de la lengua ranquel estuvo tensionada entre una visión tradicional y hegemónica y su inclusión y visibilización, que habilita la reflexión sobre el tema. En este sentido, se arriesga que la serie se inscribe en la tradición de audiovisuales sobre la frontera indígena criolla, iniciada por El último malón (Greca, 1917), en la que el documento y la recreación conviven en tensión. Además, se advierte que Otra excursión... se nutre de los filmes clásicos de frontera -considerados dramas sociales folclóricos por Lusnich (2007) - al proponer en su estructura cuadros con músicos icónicos de la escena contemporánea. La inclusión de las canciones otorga al audiovisual un efecto de anacronismo y de emotividad que comunica las temporalidades de los siglos XIX y XxI. 


\section{Referencias}

Ayala, S., Nicolosi, A. P. y Fleman, S. (2019). TV universitaria argentina y ficción seriada durante la ley SCA: representación e identidad. Revista Latinoamericana de Ciencias de la Comunicación. San Pablo, vol. 17 nro. 31.

Carrasco M. y Ramírez S. (2015). «Somos un pueblo, precisamos un territorio porque allí es donde se da la vida indígena; sin territorio no hay identidad como pueblo». Buen vivir en Argentina. Revista pueblos y fronteras digital, vol.10, no.19, San Cristóbal de Las Casas. https://doi.org/10.22201/cimsur.18704115e.2015.19.44

Doane, M. (1980). The voice in the cinema: the articulation of body and space. Yale French Studies: Cinema/Sound 60: 33-50.

Frith, S. (1996). Música e identidad. En Hall, S. y Du Gay, P. (ed), Cuestiones de identidad cultural. Buenos Aires: Amorrortu Editores.

Gilroy, P. (1990). Sounds authentic: black music, ethnicity, and the challenge of a Changing same", Black usic Research Jorunal 10 (2), pags 128-31.

Gimeno Ugalde, E y Poe Lang, K. (2017). Representaciones del mundo indígena en el cine hispanoamericano (documental y ficción). San José: Editorial Universidad de Costa Rica.

Greca, D. (2014). De la historia en el cine al cine en la historia. Potenciales como documento del filme El último malón. Revista Páginas. Universidad Nacional de Rosario. Vol. 6, nro. 10.

Hall, S. (2010). El espectáculo del “Otro”. En Hall, S., Restrepo, E., Walsh, C. y Vich, V. (Eds.), Sin garantías: Trayectorias y problemáticas en estudios culturales. Universidad Javeriana, Instituto de Estudios Peruanos y Universidad Andina Simón Bolívar, sede Ecuador. Envión Editores, pp. 349- 404.

Hall, S. (1996). ¿Quién necesita identidad? En Hall, S. y Du Gay, P. (ed), Cuestiones de identidad cultural. Buenos Aires: Amorrortu Editores.

López, M. y Rodríguez A. (2007). Una de indios y soldados en la frontera sur. Identidad y subalternidad en un western argentino. Revista Film Historia. Número Especial. Dossier Latinoamérica.

Lusnich, A. (2007). El drama social-folclórico. El universo rural en el cine argentino. Buenos Aires, Biblos.

Metz, C. (1970). El decir y lo dicho en el cine: ¿hacia una decadencia de cierto verosímil? En AAVV. Lo verosímil. Buenos Aires: Editorial Tiempo Contemporáneo.

Nahmad Rodríguez, A. D. (2007). Las representaciones indígenas y la pugna por las imágenes. México y Bolivia a través del cine y el video. Latinoamérica. Revista de Estudios Latinoamericanos, núm. 45, pp. 105-130.

Plantinga, C. (2017). Caracterización y ética en el género documental. Archivos de la Filmoteca. Revista de estudios históricos sobre la imagen, N. ${ }^{0}$ 57-58. Valencia, España.

Rodríguez, A. (2015). Historia, pueblos originarios y frontera en el cine nacional. Departamento de Ciencias Sociales. Universidad Nacional de Quilmes.

Rosenstone, R. (1997). El pasado en imágenes. El desafío del cine a nuestra idea de la historia. Barcelona: Ariel. 
Rosenstone, R. (2014). La historia en el cine. El cine sobre la historia. Madrid: Rialp.

Williams, R. (1980). Marxismo y literatura. Barcelona: Paidós

Wolf, S. (2001). Cine/Literatura. Ritos de pasaje. Buenos Aires: Paidós.

\section{Referencias de Internet}

Carranza, J. (25 de marzo de 2021). Conversatorio con el realizador Jerónimo Carranza, "Relaciones entre el audiovisual y la historia: a propósito de la serie Otra excursión a los indios ranqueles" [Zoom]. Organizado por el Diploma de Posgrado en Historia Pública y Divulgación de la Historia, CEHCMe, Universidad Nacional de Quilmes.

Contexto (2018). La serie «Otra excursión a los indios ranqueles» nominada a los premios FUNDTV. Recuperada de https://www.diariocontexto.com.ar/2018/06/14/la-serie-otraexcursion-a-los-indios-ranqueles-nominada-a-los-premios-fundtv/

Plataforma Mundo U (sitio web). Sinopsis de Otra excursión a los indios ranqueles Otra excursión a los indios ranqueles. Recuperado de https://www.mundou.edu.ar/contenidos/ capitulos/otra-excursin-a-los-indios-ranqueles/204

\section{Ficha técnica}

\section{Serie Otra excursión a los indios ranqueles}

Año: 2017

Duración: 8 episodios por 26 min

Guion: Pablo Siciliano / Nahuel Lahora /Gustavo Alonso Basada en la obra de Lucio V. Mansilla Producción general: Cristian Jure y Gustavo Alonso

Producción ejecutiva: Gloria López - Canal TV Universidad / UNLP Guillermo González Schain - UNLPam Eduardo Aguirre - UNRC -Eugenia Monti - Centro de Promoción y Producción Audiovisual / UNC- Víctor Hugo Díaz - Centro de Promoción y Producción Audiovisual / UNC

Director de producción: Miguel D’elía

Producción artística: Gustavo Alonso

Dirección y realización ficción: Jerónimo Carranza

Coordinación de producción: Paula Asprella

Producción rodaje La Pampa: Cynthia Zorrilla /Matías Torres

Casting La Pampa: Mariano Pineda Abella

Dirección de fotografía y cámara: Pablo Huerta 


\section{Notas:}

1. Fue emitida por Canal Encuentro, los jueves de junio y julio de 2020, en el horario de las 20 .

2. Mansilla fue un general del Ejército Argentino que viajó junto a dieciocho hombres casi desarmados desde Río Cuarto, Córdoba, hasta La Pampa, para firmar un tratado de paz con los ranqueles.

3. En el conversatorio, Carranza (25 de marzo de 2021) menciona, además, lo siguiente: "Yo aparte hice la edición de toda la serie, entonces tenía muy claro qué aspectos de la ficción tenía flojos o qué temas me venía bien que se reforzaran desde el tópico documental [...] un historiador de pronto lo ponía en falta o hacía referencia [...] la idea fue que quede bien mezclado esos decires actuales entrevistados con aquella ficción; entonces, en el resultado final queda bastante amalgamado lo que dicen los historiadores, los escritores, los periodistas con aquello que se ve".

4. El término se usa en el sentido dado por Metz (1970), socialmente determinado como aquello posible de ser verdadero.

5. Mary Ann Doane (1980) sostiene que la narración en off perpetúa la imagen de unidad y ahuyenta el miedo a la fragmentación en el inconsciente del espectador, mantenido la homogeneidad material del cuerpo de la película.

6. Sobre la teoría racial que aplicaba de manera diferente la distinción cultura/naturaleza a los s grupos racializados, ver Hall, S. (2010) “El espectáculo del Otro". Sobre la representación estereotipada de los indígenas en el cine, ver: Nahmad Rodríguez, A. D. (2007) “Las representaciones indígenas y la pugna por las imágenes”; Gimeno Ugalde, E y Poe Lang, K. (2017) Representaciones del mundo indígena en el cine hispanoamericano (documental y ficción); Rodríguez, A. (2015). Historia, pueblos originarios y frontera en el cine nacional y López, M. y Rodríguez A. (2007). "Una de indios y soldados en la frontera sur. Identidad y subalternidad en un western argentino".

7. Idénticos planos se repetirán en el capítulo $8 \mathrm{y}$, al respecto, es posible sostener que la repetición de planos y efectos sonoros con diferentes montajes apuntan a una gran síntesis estética, que resulta en una condensación de lo indígena.

8. Fragmento de la letra de la canción "Un cambio", de Sara Hebe, lanzada en 2012 como parte del álbum Puentera.

9. Simon Frith (1996) sostiene que si bien la identidad musical es siempre fantástica e idealiza el nosotros y al mundo social que habitamos, también es siempre real y se concreta en las actividades musicales. Hacer y escuchar música es una cuestión corporal, resultado de una actividad práctica donde interviene el lenguaje, el gesto, las significaciones corporales, los deseos y que, a la vez, está en estrecha relación con los movimientos sociales A través de ella las personas no solo se reconocen a sí mismas sino como grupos, con una organización particular de intereses individuales y sociales, de mismidad y diferencia. 10. A modo de ejemplo, en el año 2013, se convocó a una Cumbre de Pueblos Indígenas en la provincia de Formosa para dar a conocer la situación que estaban atravesando y allí se denunció un aumento del número de muertos por desnutrición, contaminación de 
tierras y aguas por empresas petroleras y fumigaciones con agrotóxicos. Según Carrasco y Ramírez (2015), desde los pueblos indígenas en la Argentina se han venido demandando otros modelos de vida que incluyen el reconocimiento de sus identidades, nuevas narrativas históricas, autonomía para decidir, así como "la denuncia de la voracidad del sistema productivo occidental que invade y destruye los bosques y contamina los ríos y el suelo; muchas condensan sus demandas en términos ontológicos, cuando se refieren a sus cosmovisiones como sistemas filosófico-ideológicos enfrentados a la civilización. El centro de estas demandas es el reclamo de autonomía y propiedad territorial”.

\begin{abstract}
This article analyzes the contextual, narrative, dramatic and aesthetic aspects of the series Another Expedition to the Ranquel Indians (2017), produced by the national universities of La Plata, La Pampa, Río Cuarto and Córdoba.

We reflect on the identities created by the audiovisual, considering the different structural elements that it combines: testimonies of specialists, scenes recreated from the literary work An Expedition to the Ranquel Indians, by Lucio V. Mansilla (1870) and music scenes. It is argued that each of these elements provide specific linking strategies with knowledge and affect. In addition, it is suggested that due to the formative function of the series, the testimonies are built from a staging that highlights its reliability and expertise and that the dramatization of textual fragments articulated with the questions and reflections of the specialists officiates a version of the story in the terms raised by Rosenstone (1997).

For its part, the series finds a strategy towards affectivity, defining a space where rigid distinctions between emotion / information are diluted, through the performativity of the musical proposal.
\end{abstract}

Keywords: University series - Lucio V. Mansilla - Indigenous peoples - audiovisual - border.

Resumo: Este artigo analisa os aspectos contextuais, narrativos, dramáticos e estéticos da série Outra excursão aos índios ranqueles (2017), produzida pelas universidades nacionais de La Plata, La Pampa, Río Cuarto e Córdoba.

$\mathrm{O}$ artigo reflete sobre as identidades construídas pelo audiovisual, considerando os diferentes elementos estruturais que combinam: depoimentos de especialistas, cenas recriadas a partir da obra literária Uma excursão aos índios ranqueles, por Lucio V. Mansilla (1870) e cenas musicais. Afirma-se que cada um desses elementos contribui com estratégias de ligação específicas com o conhecimento e o afeto. Dessa forma, postula-se que devido à função formativa da série, os depoimentos são construídos a partir de uma encenação que destaca sua confiabilidade e experiência e que a dramatização de fragmentos textuais articulados com os questionamentos e reflexões dos especialistas oficializa a versão da história nos termos propostos por Rosenstone (1997). 
Por sua vez, a série encontra uma estratégia para a afetividade, definindo um espaço onde distinções rígidas entre emoção / informação são diluídas, através da performatividade da proposta musical.

Palavras chave: série universitária - Lucio V. Mansilla - povos indígenas - audiovisual fronteira.

[Las traducciones de los abstracts fueron supervisadas por el autor de cada artículo] 